тивности интегрированного урока литературы: автореф. дис. ... канд. пед. наук. Самара, 2000. 20 с.

11. Калуцкая Е.Н. Особенности интегрированного урока литературы в старших классах средней школы (на примере литературы и немецкого языка): дис. ...канд. пед. наук. Самара, 2004. 183 с.

12. Коровина В.Я. Методические основы совершенствования устной речи учащихся в процессе изучения литературы в школе: автореф. дис. ...д-ра пед. наук. М., 1994. 39 с.

13. Загородная Л.П. О разработке интегрированного курса «иностранный язык + художественное развитие» // Иностранные языки в школе. 1992. № 3. C. $3-12$.

14. Зотеева И.Н., Зайцева Т.А. О функциях межпредметных связей при обучении французскому языку в средней школе // Иностранные языки в школе. 1995. № 1. С. 42-45.

15. Габдуллина М.Г. Разработка проблемных заданий в процессе преподавания литературы на английском языке в X-XI кл. // Иностранные языки в школе. 2005. № 4. С. 33-37.
16. Матрон Е.Д. Художественное произведение на уроках иностранного языка: учебное пособие. М., 2002. $296 \mathrm{c}$.

17. Гадоев К.Х. Интегрированное обучение иностранному (английскому) языку в неязыковых вузах республики Таджикистан: дис. ...канд. пед. наук. Душанбе, 2015. 164 с.

18. Казначеева С.Н., Репина Р.В. Интеграция иностранного языка с другими дисциплинами на основе личностно-деятельностного подхода с целью развития познавательной активности студентов [Электронный ресурс] // Интернет-журнал «Мир науки» 2016. T. 4, № 1. - http://mir-nauki.com/pdf/ 16dmn116.pdf.

19. Гиренок Г.А. Формирование коммуникативной компетенции будущих сотрудников УИС в высшей профессиональной школе: автореф. дис. ... канд. пед. наук. Самара, 2013. 25 с.

20. Рабочая программа учебной дисциплины «Иностранный (английский) язык» ФКОУ ВО СЮИ ФСИН России / сост. Г.А. Гиренок, О.О. Скобелева. Самара, 2016. 37 с.

\title{
INTEGRATED ENGLISH AND LITERATURE COURSE IN LAW SCHOOLS SPONSORED BY GOVERNMENT AGENCIES
}

(C) 2017

Skobeleva Oksana Olegovna, candidate of pedagogical sciences, deputy head of Philosophy and Humanities Department

Samara Law Institute of the Federal Penitentiary Service of Russia (Samara, Russian Federation)

Abstract. This paper deals with the problem of improving linguistic and cultural skills of students by introducing integrated foreign language and literature classes into the educational process. The integration of cultures in the departmental law institutions is an important element in the training of specialists whose competence is largely determined by their professional skills as well as by the ability to use a foreign language in terms of establishing contacts with representatives of other cultures and the ability to work independently with scientific and practical documentation and literature, to conduct business correspondence and negotiations. The work outlines the basis for the development of an integrative course of English and literature and offers a series of sessions on interdisciplinary interactions. The conducted researches have shown that interdisciplinary connections in foreign language classes have a positive impact on the quality of the educational process: cadet's horizons are expanding, motivational aspect of training is increasing, educational and research activity is becoming more active, moral education is formed, and communicative skills of trainees are developing. The obtained results testify to the need to develop such classes within any specialization and orientation, since integrated courses significantly expand cognitive and language skills of students.

Keywords: integration; integrative interactions; interdisciplinary integration; foreign language studies; fiction book; communicative competence; cadet; law school; level of knowledge; cultural context; vocational training; communication; lexical units.

УДК 378.147

Статья поступила в редакцию 03.05.2017

\section{ОСОБЕННОСТИ ИЗУЧЕНИЯ КУРСА «НЕКЛАССИЧЕСКИЕ ЗАДАЧИ МАТЕМАТИЧЕСКОЙ ФИЗИКИ» В УСЛОВИЯХ РЕАЛИЗАЦИИ КОМПЕТЕНТНОСТНОГО ПОДХОДА К ПОДГОТОВКЕ МАГИСТРОВ ПЕДАГОГИЧЕСКОГО ОБРАЗОВАНИЯ}

(C) 2017

Холодовский Святослав Евгеньевич, доктор физико-математических наук, профессор кафедры фундаментальной и прикладной математики, теории и методики обучения математике Кононенко Наталья Васильевна, кандидат педагогических наук, доцент кафедры фундаментальной и прикладной математики, теории и методики обучения математике Токарева Юлия Сергеевна, кандидат физико-математических наук, декан факультета естественных наук, математики и технологий Забайкальский государственный университет (2. Чита, Российская Федераиия)

Аннотация. В статье рассматриваются теоретические, методологические и методические аспекты реализации компетентностного подхода к подготовке магистров педагогического образования физико-математи- 
Холодовский С.Е., Кононенко Н.В., Токарева Ю.С.

ческой направленности в процессе изучения курса «Неклассические задачи математической физики» в высшем образовательном учреждении. Описываются цели, задачи и актуальность дисциплины, направленные на осознание магистрантами практического характера решения неклассических задач математической физики. В соответствии с федеральным государственным стандартом высшего образования представлены компетенции, на формирование которых направлено освоение данного учебного курса. Описан процесс формирования заявленных компетенций, который проходит через несколько уровней. Для каждого результата обучения выделены и подробно описаны соответствующие уровни сформированности компетенций (пороговый, стандартный, эталонный). Приводятся авторские материалы, отражающие методику формирования профессиональных компетенций при подготовке магистров математического образования на базе Забайкальского государственного университета. Практический аспект реализации компетентностного подхода в подготовке рассматривается на материале данного учебного курса через краевую задачу математической физики в области с пленочными включениями (задача для сильно проницаемой пленки). Представленный в статье положительный опыт и полученные материалы могут быть полезны преподавателям вузов.

Ключевые слова: компетенция; компетентностный подход; уровень сформированности компетенций; подготовка магистра педагогического образования; математическое образование; неклассические задачи математической физики; задача для сильно проницаемой пленки; методы решения краевых задач математической физики.

В настоящее время система российского образования переживает преобразования, связанные с внедрением Болонского процесса. Одним из ключевых моментов включения России в европейское пространство высшего образования является реализация компетентностного подхода. К одной из основных проблем современного процесса образования относится подготовка будущего выпускника вуза, который в короткие сроки может приспособиться к потребностям работодателей. В этих условиях становится актуальной образовательная парадигма, когда, с одной стороны, должны учитываться интересы личности, адекватные тенденциям интенсивного развития общества, а с другой стороны, модернизация общего образования, требующая учителя, который мог бы решать новый класс возникающих на практике профессиональных задач на достаточно высоком уровне [1-4].

Для решения указанных задач знаний и умений, сформированных в условиях классического университетского образования, явно недостаточно. Современное общество требует, чтобы выпускник высшей школы был уже компетентным специалистом, а не носителем некой системы знаний в определенной области. Иными словами, он должен обладать профессиональной компетентностью. Компетентностный подход меняет взгляд на результат высшего образования с понятий «обученность», «образованность» на «компетенция», «компетентность», «компетентностный подход». В работах В.И. Байденко [5], Э.Ф. Зеера [6], И.А. Зимней [7], Н.В. Кузьминой [8], А.К. Марковой [9] и др. [10; 11] раскрываются и сравниваются понятия «компетенция», «компетентность», «компетентностный подход».

Нам ближе точка зрения американского психолога Дж. Равена, который определял компетентность как специфическую способность эффективного выполнения конкретных действий в предметной (физико-математической) области. Эта способность включает в себя узко предметные знания, особого рода предметные навыки, способы мышления, понимание ответственности за свои действия [12;13].

В Концепции модернизации российского образования заявлено о необходимости введения компе- тентностного подхода в образовании. При подготовке будущего учителя математики, физики и информатики очень важно понимание студентами практического и прикладного аспектов содержания учебной дисциплины по выбору «Неклассические задачи математической физики». При изучении данной дисциплины явно проявляется единство теории и практики. Особое место дисциплины «Неклассические задачи математической физики» в учебном плане магистерской программы «Математическое образование» определяется фундаментальным характером ее содержания. Для успешной реализации компетентностного подхода при подготовке магистров математического образования на базе Забайкальского государственного университета успешно функционирует лаборатория прикладной математики, одним из направлений деятельности которой является решение проблем экранирования загрязненных зон, теплоизоляции зданий, применения композитных материалов, развития нанотехнологий и т.д. в математических моделях. Решение указанных проблем приводит к постановке и решению краевых задач математической физики в областях с пленочными включениями. Целью нашей работы являлось раскрытие особенностей изучения курса «Неклассические задачи математической физики» в условиях реализации компетентностного подхода к подготовке магистров педагогического образования.

В университетских курсах математической физики рассматриваются классические краевые задачи в однородных областях (без пленочных включений). Как показано в работах $[14 ; 15]$, если область содержит пленочное включение, то на этом включении для искомых функций (потенциалов) должны выполняться обобщенные условия сопряжения, что приводит к неклассическим краевым задачам математической физики. Сильно проницаемая пленка моделируется бесконечно тонким слоем с бесконечно большой проницаемостью. При этом сильно проницаемые пленки характеризуются соответственно параметром:

$$
A=\lim _{l \rightarrow 0, k \rightarrow \infty} l k
$$

где $l$ - толщина пленки, а $k$ - ее проницаемость. 
Задачи с пленочными включениями рассматриваются на курсах по выбору в рамках магистерских программ «Математическое образование» и «Физико-математическое образование». Курс «Неклассические задачи математической физики» направлен на достижение такой цели, как формирование готовности анализировать результаты научных исследований в области математической физики и применять их к решению неклассических задач, имеющих прикладной характер.

Для этого должны быть решены следующие задачи:

- сформировать представления магистрантов о методах решения краевых задач математической физики и особенностях применения их к решению неклассических задач;

- создать условия для формирования умения решать краевые задачи в областях, содержащих пленочные включения различных форм;

- способствовать пониманию магистрантами прикладного характера неклассических задач математической физики.

При реализации компетентностного подхода на первый план выходит практическая составляющая профессионального образования. Освоение данной учебной дисциплины направлено на формирование профессиональных компетенций. Магистрант в результате освоения данной дисциплины:

1) способен анализировать результаты научных исследований, применять их при решении конкретных научно-исследовательских задач в сфере науки и образования, самостоятельно осуществлять научное исследование;

2) готов использовать индивидуальные креативные способности для самостоятельного решения исследовательских задач;

3) знает концептуальные и теоретические положения науки математика, владеет научными основами современной математики, необходимыми для ее трансляции обучающимся в соответствии с образовательной программой.

Процесс формирования компетенций проходит через несколько уровней (табл. 1).

таблица 1 - Уровни сформированности компетенций

\begin{tabular}{|c|c|}
\hline $\begin{array}{c}\text { Резуль- } \\
\text { тат обу- } \\
\text { чения }\end{array}$ & $\begin{array}{c}\text { Уровень } \\
\text { сформированности компетенций }\end{array}$ \\
\hline \multirow{3}{*}{ Знать } & $\begin{array}{l}\text { Пороговый: } \\
\text { 1) базовые термины в проблемно- } \\
\text { предметном поле дисциплины; } \\
\text { 2) основные методы математической фи- } \\
\text { зики. }\end{array}$ \\
\hline & $\begin{array}{l}\text { Cтандартный: } \\
\text { 1) терминологическую систему матема- } \\
\text { тической физики; } \\
\text { 2) области приложения аппарата матема- } \\
\text { тической физики. }\end{array}$ \\
\hline & $\begin{array}{l}\text { Эталонный: } \\
\text { 1) содержательные элементы математи- } \\
\text { ческой и их определения; } \\
\text { 2) методы решения задач математической } \\
\text { физики. }\end{array}$ \\
\hline
\end{tabular}

\begin{tabular}{|c|c|}
\hline \multirow{3}{*}{ Уметь } & $\begin{array}{l}\text { Пороговый: } \\
\text { 1) классифицировать задачи математиче- } \\
\text { ской физики; } \\
\text { 2) применять алгоритмы решения неклас- } \\
\text { сических задач в простейших случаях. }\end{array}$ \\
\hline & $\begin{array}{l}\text { Стандартный: } \\
\text { 1) применять основные методы решения } \\
\text { краевых задач математической физики; } \\
\text { 2) проявлять (осуществлять) элементы } \\
\text { исследовательской деятельности при ре- } \\
\text { шении ранее не изученных (принципи- } \\
\text { ально новых) задач. }\end{array}$ \\
\hline & $\begin{array}{l}\text { Эталонный: } \\
\text { 1) выбирать метод решения задач мате- } \\
\text { матической физики и решать краевые за- } \\
\text { дачи в областях, содержащих пленочные } \\
\text { включения различных форм; } \\
\text { 2) самостоятельно осуществлять научное } \\
\text { исследование в области неклассических } \\
\text { задач математической физики. }\end{array}$ \\
\hline \multirow{3}{*}{ Владеть } & $\begin{array}{l}\text { Пороговый: } \\
\text { 1) основными понятиями математической } \\
\text { физики для решения краевых задач в об- } \\
\text { ластях, содержащих пленочные включе- } \\
\text { ния различных форм; } \\
\text { 2) основными методами и алгоритмами } \\
\text { решения краевых задач в областях, со- } \\
\text { держащих пленочные включения различ- } \\
\text { ных форм. }\end{array}$ \\
\hline & $\begin{array}{l}\text { Стандартный: } \\
\text { 1) методами решения большого перечня } \\
\text { задач, подбора и комбинирования мето- } \\
\text { дов (алгоритмов) решения неклассиче- } \\
\text { ских задач математической физики; } \\
\text { 2) материалом дисциплины на уровне } \\
\text { понимания. }\end{array}$ \\
\hline & $\begin{array}{l}\text { Эталонный: } \\
\text { 1) умением осуществлять поиск новых } \\
\text { методов и алгоритмов решения неклас- } \\
\text { сических задач математической физики; } \\
\text { 2) материалом дисциплины на уровне ос- } \\
\text { мысления и практического применения. }\end{array}$ \\
\hline
\end{tabular}

Рассмотрим практический аспект реализации компетентностного подхода в подготовке магистра педагогического образования на материале данного учебного курса. Основываясь на требованиях ФГОС ВО, учитывая набор ключевых компетенций будущего педагога, на наш взгляд, содержание курса «Неклассические задачи математической физики» должно иметь следующий вид:

1) Особые точки аналитических функций, их динамический смысл;

2) Постановка краевых задач в кусочно-неоднородных областях;

3) Решение задач сопряжения на кусочно-однородной плоскости;

4) Решение задач с обобщенными условиями сопряжения на пленочных включениях.

Магистранты овладевают методами решения неклассических задач математической физики в процессе решения конкретных задач как теоретического, так и прикладного характера. Наиболее ярким примером, относящимся к первому виду, можно отнести задачу для сильно проницаемой пленки. 
Задача для сильно проницаемой пленки. Рассмотрим верхнюю полуплоскость $D=(x \in R) \times(y>0)$, разделенную прямой $x=0$ на два квадранта $D_{1}(x<0)$ и $D_{2}(x>0)$ с различной проницаемостью $k_{i}$ в $D_{i}$, когда прямая $x=0$ является сильно проницаемой пленкой. В данной неоднородной полуплоскости $D(y>0)$ относительно искомых функций $u_{i}(x, y)$ в $D_{i}(i=1,2)$ рассмотрим первую краевую задачу для уравнения Лапласа (задачу Дирихле):

$$
\begin{gathered}
\Delta u_{i}(x, y)=0, \quad y>0, \quad u_{1 \mid y=0, x<0}=0, \\
u_{2 \mid y=0, x>0}=\varphi(x), \\
x=0: u_{2}=u_{1}, \\
k_{2} \partial_{x} u_{2}-k_{1} \partial_{x} u_{1}=A \partial_{x}^{2} u_{1},
\end{gathered}
$$

где $\Delta=\partial^{2} / \partial x^{2}+\partial^{2} / \partial y^{2}, \varphi(x)$ - заданная кусочногладкая функция, интегрируемая при $0<x<\infty$, $\varphi(x)=0$ в некоторой окрестности $x=0 ; A$ - параметр из (1); условия сопряжения (3) на сильно проницаемой пленке, полученные в работе [14]. Найти функции $u_{i}(x, y)$, удовлетворяющие условиям (2) и (3).

Опираясь на требование формирования третьей компетенции, для решения этой задачи магистрант должен знать: задачу Дирихле (первую краевую задачу для уравнения Лапласа); интеграл Фурье; формулу Пуассона.

Также решатель должен владеть:

- методами решения алгебраических систем;

- методами интегрирования;

- методами вычисления несобственных интегралов;

- методами решения обыкновенных дифференциальных уравнений;

- методами разложения функции в интеграл Фурье.

Рассмотрение таких дополнительных вопросов, как решение краевых задач в кусочно-однородной и кусочно-неоднородной полуплоскостях и полосе, способствует повышению общего уровня математической культуры будущего учителя, его общетехнических и профессиональных компетенций.

Для проверки и оценки сформированности каждой из заявленных компетенций у каждого магистранта требуется разработать блок заданий, касающихся разных аспектов профессиональной деятельности $[16 ; 17]$. Основную часть этого блока составляют задачи экранирования разными видами пленки. Также для самостоятельной постановки и решения исследовательских задач в области неклассической физики предлагается варьирование модели за счет модификации разных видов пленки. И, самое важное, полученный результат должен быть интерпретирован соответствующим образом, что говорит о владении магистрантами аппаратом математического моделирования.

Отметим, что при проведении практических занятий по данной дисциплине применяются различные виды взаимодействия и интерактивные методы: проблемные дискуссии, проектные методы, индивиду- альные и групповые задания, анализ ситуаций и т.д. Они способствуют развитию исследовательских умений магистрантов, дают им возможность использовать теоретические знания в практической деятельности [18-20].

Итак, одним из эффективных способов повышения качества подготовки будущих магистров педагогического образования при освоении курса «Неклассические задачи математической физики» являются подходы и методы, реализуемые в рамках компетентностного подхода. Практика показывает, что подобные подходы позволяют активизировать учебную и познавательную деятельность магистрантов, способствует развитию индивидуальных креативных способностей, а значит, повышает их конкурентоспособность и востребованность на рынке труда.

\section{СПИСОК ЛИТЕРАТУРЫ:}

1. Куприянов Р.В., Виленский А.А., Куприянова Н.Е. Болонский процесс в России: специфика и сложности реализации // Вестник Казанского технологического университета. 2014. Т. 20, № 20. С. 412-416.

2. Быков А.А. Особенности реализации компетентностного подхода при подготовке специалистов прикладной информатики и вычислительной техники на базе смоленских вузов // Современная педагогика. 2014. № 10. С. 52-55.

3. Добудько Т.В., Пугач В.И., Бурцев Н.П., Пугач О.И., Тюжина И.В., Данилюков П.А. Формирование информационно-технологической компетентности магистров педагогического образования в контексте развития электронного образовательного пространства педагогического вуза // Самарский научный вестник. 2017. Т. 6, № 1(18). С. 182-188.

4. Манакова Е.В. Требования работодателей к выпускникам вузов: компетентностный подход // Вестник Московского городского педагогического университета. Серия: Экономика. 2014. № 1(25). С. 1525 .

5. Байденко В.И. Компетентностный подход к проектированию государственных образовательных стандартов высшего профессионального образования: метод. пособие. М.: Исследовательский центр проблем качества подготовки специалистов, 2005. $114 \mathrm{c}$.

6. Зеер Э.Ф., Павлова А.М., Сыманюк Э.Э. Модернизация профессионального образования: компетентностный подход. М.: МПСИ, 2005. 216 с.

7. Зимняя И.А. Ключевые компетенции - новая парадигма результата образования // Высшее образование сегодня. 2003. № 5. С. 34-42.

8. Кузьмина Н.В. Профессионализм личности преподавателя и мастера производственного обучения. М.: Высшая школа, 1990. 119 с.

9. Маркова А.К. Психология труда учителя. М.: Просвещение, 1993. 190 с.

10. Булдашева О.В. Реализация компетентностного подхода в процессе преподавания дисциплины «Основы здорового образа жизни» // Научно-методический электронный журнал «Концепт». 2014. T. 26. C. $316-320$.

11. Sitnikova M.I., Isaev I.F., Kormakova V.N., Minenko N.V., Shumakova I.A. Teaching Quality Assurances in Higher Education Institution: Competencebased Approach // The Social Sciences (Pakistan). 2016. T. 11, № 10. C. 2376-2380. 
12. Равен Дж. Компетентность в современном обществе: выявление, развитие и реализация. М.: Когито-Центр, 2002. 396 с.

13. Асланов Р.М., Синчуков А.В. Компетентностный подход в подготовке будущего учителя информатики и математики // Преподаватель XXI век. 2008. № 2. С. 11-16.

14. Холодовский С.Е. Метод свертывания разложений Фурье в решении краевых задач с пересекающимися линиями сопряжения // Журнал вычислительной математики и математической физики. 2007. Т. 47, № 9. С. 1550-1556.

15. Холодовский С.Е. Метод свертывания разложений Фурье. Случай обобщенных условий сопряжения типа трещины (завесы) в кусочно-неоднородных средах // Дифференциальные уравнения. 2009. T. 45, № 6. C. $855-859$.

16. Рогова Н.В., Костина Е.В. Учебная программа по математике в рамках компетентностного подхода // Перспективы науки. 2017. № 1(88). С. 61-66.
17. Данилов Д.А., Корнилова А.Г. Компетентностный подход к профессиональной подготовке будущих педагогов // Интерактивная наука. 2017. № 5(15). C. 50-52.

18. Энбом Е.А., Иванова В.А. Особенности формирования и развития исследовательской компетентности студентов в процессе изучения дисциплины «Высшая математика» в техническом вузе // Самарский научный вестник. 2015. Т. 6, № 1(10). С. 140144.

19. Кондратенко Е.И., Касимова С.К., Ломтева Н.А., Салхенова А.А., Сорокин А.П. Реализация компетентностного подхода при освоении разделов физики и биофизики // Гуманитарные исследования. 2016. № 4(60). C. 157-163.

20. Nelunova E.D., Artemiev I.T., Davydova E.M., Innovative Activity: Educational Innovations in the Context of Competence-Based Approach // Russian Linguistic Bulletin. 2016. № 2(6). C. 105-107.

\section{FEATURES OF THE COURSE «NON-CLASSICAL PROBLEMS OF MATHEMATICAL PHYSICS» IN THE CONDITIONS OF REALIZATION OF COMPETENCE APPROACH TO THE TRAINING OF MASTERS OF PEDAGOGICAL EDUCATION}

(C) 2017

Kholodovskii Svyatoslav Yevgenyevich, doctor of physical and mathematical sciences, professor of Fundamental and Applied Mathematics, Theory and Methods of Teaching Mathematics Department

Kononenko Natalya Vasilievna, candidate of pedagogical sciences, associate professor of Fundamental and Applied Mathematics, Theory and Methods of Teaching Mathematics Department

Tokareva Julia Sergeevna, candidate of physical and mathematical sciences, dean of Natural Sciences, Mathematics and Technology Faculty

Transbaikal State University (Chita, Russian Federation)

Abstract. This paper discusses theoretical, methodological and methodical aspects of realization of the competence approach to the training of masters majoring in pedagogical education in Physics and Mathematics during the course «Non-Classical Problems of Mathematical Physics» study at higher educational institutions. The paper describes the goals, objectives and relevance of the course aimed at understanding practical solutions of non-classical problems of mathematical Physics by undergraduates. In accordance with the federal state standard of higher education the authors present the competences that are developed during this course. The authors describe the process of the declared competencies development. This process has several levels. For each learning outcome the authors describe appropriate levels of competence (threshold, standard, reference). The authors' materials reflect methodology of professional competences development in the process of training masters majoring in mathematical education on the basis of Transbaikal State University. The practical aspect of the competence approach implementation is examined on the basis of this training course through the boundary value problem of mathematical Physics in the field with film inclusions (the problem for a strongly permeable film). The positive experience presented in the paper and the received materials can be useful for university teachers.

Keywords: competence; competence approach; level of competence development; training of masters majoring in pedagogical education; mathematical education; non-classical problems of mathematical physics; problem for strongly permeable film; methods for solving boundary value problems of mathematical physics. 